\title{
Álcool e agentes comunitários de saúde: um estudo das representações sociais
}

\author{
Alessandra Ramos Castanha \\ Ludgleydson Fernandes de Araújo ${ }^{1}$
}

\begin{abstract}
Resumo
Esta pesquisa teve como objetivo verificar as Representações Sociais de Agentes Comunitários de Saúde (ACS’s) acerca do uso do álcool. Participaram 70 ACS's da cidade de Ipojuca -PE, de ambos os sexos, com média de idade 26 anos. Foram utilizados como instrumentos entrevistas semi-estruturadas e o Teste de Associação Livre de Palavras. O material coletado pela entrevista foi categorizado pela análise de conteúdo temática e os do teste de associação foram processados pelo software Tri-Deux-Mots, através da análise fatorial de correspondência. Os dados obtidos entre os ACS's revelaram representações do álcool como uma droga prejudicial à saúde e que pode levar à morte. No que se refere às conseqüências na vida do usuário, de forma majoritária os ACS’s apontaram os problemas familiares decorrentes do álcool. Conclui-se da necessidade de intervenções no âmbito da prevenção primária com o intuito de diminuir as conseqüências advindas do uso abusivo do álcool.

Palavras-chave: Álcool; Agentes comunitários de saúde; Representações sociais.
\end{abstract}

\section{Alcohol and communitarian agents of health: a study of the social representations}

\begin{abstract}
This research had as objective to verify the social representations of communitarian agents of health (ACS's) regarding the use of alcohol. Seventy ACS's residents of the city of Ipojuca-PE, including both male and female genders, and with average age of 26 years participated in this project. It was utilized as instruments semi-structured interviews and the Test of Free Association of Words. The data acquired by the interviews was categorized by the Bardin's analysis of thematic content (1977) whereas the data from the test of association was processed by the Tri-deuxmots software through the factorial analysis of correspondence. The data obtained from the ACS's made possible to represent the alcohol as a harmful drug for the health which can lead to death. Concerning the consequences on the user's life, the majority of the ACS's objectified the family problems resulting from alcohol abuse. In conclusion, there is a necessity of the formation of public health policies, including the fundamental role of the ACS's as social actors in the primary prevention of the abusive drug use within the Brazilian reality.

Keywords: Alcohol; Communitarian agents of health; Social representations.
\end{abstract}

A magnitude do problema do uso indevido de drogas, dentre elas o álcool, ganhou proporções tão alarmantes que, na atualidade, é um desafio da saúde pública no país. O uso indevido de drogas se reflete nos diversos segmentos da sociedade por sua relação comprovada com os agravos sociais, tais como: acidentes de trânsito e de trabalho, violência domiciliar e crescimento da criminalidade (Barros, 2004).

O uso de bebidas alcoólicas é uma prática bastante freqüente, aceita e reforçada pela sociedade, tendo seu início, muitas vezes, na adolescência. Mesmo sabendo que o alcoolismo leva alguns anos para se instalar no organismo, acredita-se que o uso precoce de bebidas etílicas pode vir a contribuir para o estabelecimento da dependência alcoólica mais cedo, ou seja, ainda numa fase produtiva da vida, em que o sujeito teria uma boa condição de saúde para trabalhar ou estudar, o que acaba deixando de lado devido à sua dependência (Bertolote, 1997).

De acordo com pesquisa sobre o uso de drogas na realidade brasileira, desenvolvida por Carlini, Galduróz e Noto (2001), no Centro Brasileiro de Informações acerca de Drogas Psicotrópicas - CEBRID, em 107 cidades brasileiras com mais de 200 mil habitantes, constatou-se que das pessoas entrevistadas 53,2 \% já tinham consumido álcool alguma vez na vida e 11,2\% eram dependentes da droga.

Apesar do fato de existirem muitos tipos de drogas disponíveis na sociedade contemporânea, podese destacar um aumento significativo, sobretudo, das drogas ditas lícitas, como o álcool $(53,2 \%)$ e o tabaco (39\%), isto aponta para o fato da importância de inves-

\footnotetext{
${ }^{1}$ Endereço para correspondência:

Rua Antônio Leopoldo Batista, 17 apto. 306 - Bairro Bancários - 58051-110 - João Pessoa-PB

Tel: (83) 216 7006, 216 7675, 2550536

E-mail: ludgleydson@yahoo.com.br
} 
tigação científica, posto que este fenômeno possibilita o surgimento de uma gama de fatores socioafetivos e psicocognitivos (Carlini, Galduróz \& Noto, 2001).

Os dados anteriormente mencionados apontam para uma preocupação acerca dos danos que o uso abusivo do álcool pode ocasionar nos diversos segmentos da sociedade, de modo que é importante a inserção do objeto biopsicossocial nas pautas de pesquisas e intervenções científicas. Os Agentes Comunitários de Saúde (ACS's) são atores que podem contribuir na diminuição do quadro do uso de drogas, com a intervenção na educação preventiva em saúde.

Considera-se o álcool uma droga psicoativa que, dependendo de alguns fatores, como dosagem, freqüência do consumo e circunstâncias, pode causar ou não problemas de nível orgânico, psicológico e social, caracterizando, então, o alcoolismo como um fenômeno complexo que atinge todas as classes sociais de diversos países do mundo. Esse conceito foi bastante modificado durante os anos, antes de ser definido pela OMS como Síndrome de Dependência do Álcool- DAS (Barros, 2000).

A DAS baseia-se em sete sinais e sintomas cardinais: empobrecimento do repertório de ingestão; relevância da bebida; aumento da tolerância ao álcool; sintomas repetidos de abstinência (tremores, náuseas, sudorese e perturbações do humor básico); alívio ou esquiva dos sintomas de abstinência através de mais bebida; percepção subjetiva da compulsão a beber e reinstalação rápida da tolerância após quebra da abstinência (Barros, 2000, 2004; Edwards, 1995).

Ela traz uma série de conseqüências para o indivíduo como: a estigmatização instalada no grupo de alcoolistas pela sociedade que, muitas vezes, é visto como viciado, bêbado e vagabundo (Barros, 2000, Fender, 1996), sendo também representado como sujeito sem vontade. Tal estigmatização acaba levando esse grupo à marginalização e exclusão do restante da população.

O uso do álcool e de outras drogas é um fenômeno antigo que tem acompanhado a história da humanidade e vem crescendo abusivamente nos dias atuais. Sabe-se que o uso contínuo do álcool pode levar ao alcoolismo, que consiste num fenômeno complexo que provoca alterações nos diversos órgãos e sistemas, além de problemas sociais, atingindo a família, o trabalho, as relações sociais, a situação financeira, a justiça e a polícia.

A presente pesquisa abordará as Representações Sociais (RS) do álcool elaboradas por ACS's. A importância dessa temática se dá pelo aumento substancial de novos casos de uso indevido do álcool na realidade brasileira e, em especial no município de Ipojuca-
PE, onde foi observado em estudo realizado por Quintela e cols. (2004) que cerca de $62 \%$ dos adolescentes estudados já fizeram uso de bebidas alcoólicas pela primeira vez na vida e 58, 2\% dos pais dos adolescentes fazem uso do álcool.

A investigação científica poderá contribuir no sentido de conhecer as diversas facetas que compõem o consumo exagerado de drogas e a formação de profissionais para lidar com a temática e na formulação/implementação de políticas públicas e programas de prevenção e tratamento a serem realizados na realidade brasileira.

O Ministério da Saúde vem definindo, ao longo do tempo, estratégias que visam ao fortalecimento da rede de assistência aos usuários de álcool e outras drogas, com ênfase na reabilitação e reinserção social dos mesmos na sociedade (Ministério da Saúde, 2000). Destaca-se o papel de agente multiplicador de informações preventivas ao uso abusivo de drogas nas comunidades exercido pelos ACS's, que têm realizado um canal de comunicação entre a população e os gestores em saúde (Silva \& Dalmaso, 2002).

Com relação às ações de prevenção ao uso indevido de drogas propostas atualmente pelo Ministério da Saúde, pode-se citar o Programa de Saúde da Família (PSF), que vem executando ações nesse sentido. O PSF pode funcionar como um catalisador de ações de prevenção, promoção e recuperação da saúde das pessoas com problemas relacionados ao álcool, assim como a outras drogas, de forma integral e contínua. Dessa forma, é necessário investir em ações que procurem trazer uma formação diversificada e consistente para toda a equipe do PSF, com relação aos determinantes do processo saúde/doença.

O PSF é formado, basicamente, por uma equipe multiprofissional composta por médico, enfermeiro, auxiliar de enfermagem e ACS's. É com esse último grupo, o dos ACS's, que a presente pesquisa será focalizada, tendo em vista que os mesmos possuem um papel fundamental na prevenção/tratamento das drogas junto à comunidade, sendo uma de suas funções determinadas pelo Ministério da Saúde, e por serem eles um elo essencial na construção do vínculo entre a equipe $\mathrm{e}$ as famílias e no processo de vigilância à saúde, a fim de acompanhar e intervir nos grupos vulneráveis ao adoecimento e às condições socioambientais desfavoráveis.

Os ACS's devem trabalhar com famílias de base geográfica definida. Eles são responsáveis pelo acompanhamento de, no máximo, 150 famílias ou 750 pessoas, e precisa morar, há pelo menos dois anos, na área onde desempenha suas atividades. Tem como papel desenvolver atividades de prevenção das doenças e promoção da saúde, através de visitas domiciliares e de

Psico-USF, v. 11, n. 1, p. 85-94, jan./jun. 2006 
ações educativas individuais e coletivas nos domicílios e na comunidade. (Ministério da Saúde, 2000; Silva \& Dalmaso, 2002).

Dentro dessa perspectiva, os ACS's tem como um de seus deveres orientar e aconselhar as famílias sobre a verdadeira dimensão do abuso do álcool e das suas conseqüências, ensinando as pessoas a cuidarem e preservarem a sua saúde e, em caso de necessidade, encaminhar os indivíduos para um atendimento mais especializado nos serviços da rede pública de saúde. Sempre respeitando os princípios dos valores humanos e culturais dos cidadãos, entre eles o uso da linguagem correta e acessível no oferecimento de uma informação objetiva, clara e honesta, em resumo, educativa e eficaz.

Diversos estudos têm sido realizados para fundamentar programas de prevenção e outros tipos de intervenções que visem ao controle do uso indevido do álcool, no entanto, Tura (1998) coloca que os paradigmas tradicionais de Educação para a Saúde pressupõem que os comportamentos saudáveis são resultantes de opções individuais, baseadas em esquemas racionais fundamentados em informações disponíveis. Essa perspectiva dificulta o enfrentamento de questões complexas relacionadas com o controle e prevenção de doenças, como por exemplo, o alcoolismo, por não contemplar as dimensões coletivas ou sociais referentes à saúde.

A importância de estudos relacionados à prática de saúde no campo das RS está na possibilidade de verificar os processos e mecanismos pelos quais o sentido do objeto em estudo é construído pelos sujeitos concretos, em suas relações cotidianas, de modo que os conhecimentos apreendidos junto aos atores sociais possam auxiliar em intervenções de educação preventiva em saúde.

O Agente Comunitário de Saúde, por ser um morador da comunidade, representa uma riqueza de possibilidades, pois conhece as pessoas a quem atende, tem a mesma linguagem, passa por situações parecidas, divide crenças semelhantes. Uma orientação levada por um cidadão nessas condições oferece credibilidade que dificilmente as palavras de um técnico da saúde atingiriam.

Urge, assim, a necessidade de pesquisas que contemplem as RS desses profissionais acerca do álcool, enquanto conhecimento que poderá contribuir nas suas práticas, no âmbito da intervenção e promoção da saúde. Diante dessas premissas, esta pesquisa objetiva apreender as RS do álcool por parte dos Agentes Comunitários de Saúde (ACS's) do município de IpojucaPE.

Psico-USF, v. 11, n. 1, p. 85-94, jan./jun. 2006

\section{Teoria das Representacões Sociais}

Para Moscovici (1978), as RS compreendem pensamentos, sentimentos, emoções, práticas, afetos e cognição, que se apresentam em constante mudança no tempo e na história. As RS são como o conjunto organizado de informações, atitudes, crenças que um indivíduo ou um grupo elabora a propósito de um objeto, de uma situação, de um conceito, de outros indivíduos ou grupos, apresentando-se, portanto, como uma visão subjetiva e social da realidade (Abric, 2000).

Ainda nesse sentido, Moscovici (1978, 1984, 2003) coloca que toda representação é construída na relação do sujeito com o objeto representado, não existindo representação sem objeto. Desse modo, uma RS não pode ser compreendida enquanto processo cognitivo individual, uma vez que é reproduzida no intercâmbio das relações e comunicações sociais. $\mathrm{O}$ autor ainda menciona que o objeto, seja ele humano, social, material ou uma idéia, será apreendido através da comunicação.

As RS são como sistemas de interpretação que regem nossa relação com o mundo e com os outros, orientando e organizando nossas condutas, estando ligadas a sistemas de pensamento mais amplos, ideológicos ou culturais, a um estado de conhecimentos científicos, assim como à condição social e à esfera da experiência privada e afetiva dos indivíduos (Jodelet, 2001).

Na elaboração das RS se faz necessária a contribuição de dois fatores: a objetivação e a ancoragem, os quais são responsáveis pela interpretação e atribuição de significados do objeto social, neste estudo, o álcool. Para Moscovici, esses fatores são condições sine qua non, pois ambos colaboram na maneira como o social transforma um conhecimento em representação e a maneira como esta transforma o social, indicando a interdependência entre a atividade psicológica e suas condições sociais.

Para Sá (1993), o processo de representar socialmente emerge da materialização dos conceitos abstratos comuns ao grupo, o que se denomina de objetivação, ao mesmo tempo em que cria um contexto inteligível ao objeto representado, ou sua integração cognitiva, o que é denominado de ancoragem. Nesse processo, a representação tem por objetivo transformar em familiar o não-familiar.

As RS vêm sendo bastante utilizadas em estudos no âmbito da saúde. Uma das primeiras autoras a contemplar a temática no campo das RS foi Herzlich (1986). Para ela, as RS são atendidas em nossa sociedade por um saber particularmente legítimo e forte - a medicina -, em que saúde e doença constituem um dos mais pertinentes objetos de estudo da relação da repre- 
sentação social, do pensamento comum ao pensamento científico.

Diante dessas premissas, verifica-se que o estudo das RS mostra-se perfeitamente adequado para a investigação da temática do álcool, especialmente, quando tem por finalidade apreender o conhecimento acerca dessa substância psicoativa e suas conseqüências na sociedade contemporânea.

\section{Método}

Campo de Investigação

O presente estudo foi realizado no município de Ipojuca, localizado na Zona da Mata, Sul do estado de Pernambuco. O locus dessa investigação deu-se na cidade devido a estudo realizado anteriormente por Quintela e cols. (2004), constatando que 62\% dos adolescentes já haviam feito uso de bebidas alcoólicas pela primeira vez na vida e 58, 2\% dos seus pais fazem uso do álcool. Esses dados apontam para a necessidade premente de ações de intervenção na prevenção primária no que tange ao uso abusivo do álcool, destacando-se o papel desempenhado pelos ACS's enquanto educadores em saúde preventiva.

\section{Participantes}

Participaram desta pesquisa 70 de um total de 104 ACS's, escolhidos aleatoriamente, de forma nãoprobabilística, intencional e acidental, de ambos os sexos (13\% masculino e $87 \%$ feminino), com média de idade de 26 anos. Optou-se, na presente pesquisa, por não considerar as diferenças de gênero e idade na estruturação dos grupos.

\section{Instrumentos}

Para coleta dos dados foram utilizadas entrevistas semi-estruturadas e a técnica de Associação Livre de Palavras. As entrevistas foram divididas em duas partes: a primeira, constituída de itens referentes à identificação sociodemográfica dos participantes, definindo o seu perfil; e a segunda, composta por uma questão norteadora, a saber: "O que você sabe sobre o álcool?". Também foi utilizada a Técnica de Associação Livre de Palavras, que é uma técnica bastante difundida no âmbito da Psicologia Social, principalmente, quando se trabalha com o suporte teórico das RS, uma vez que possibilita acesso aos conteúdos periféricos e latentes (Di Giacomo,1981; Le Boudec,1984; De Rosa,1988; Nóbrega \& Coutinho, 2003; Coutinho, Araújo \& Gontiès, 2004). Neste estudo foi utilizado um estímulo indutor: álcool, previamente definido, tendo como pressuposto o objeto investigado, bem como os atores sociais que fazem parte desta investigação (ACS’s).

\section{Procedimentos de coleta dos dados}

Realizou-se um estudo piloto com o intuito de verificar a boa adequação dos instrumentos, e verificouse a validade semântica dos mesmos; em seguida, efetuou-se o estudo definitivo. Inicialmente, foi estabelecido contato com a coordenação da Secretaria de Saúde, com a finalidade de obter a listagem dos ACS's; posteriormente, verificou-se a disposição dos mesmos a participar de forma voluntária desta pesquisa. $\mathrm{Na}$ oportunidade, explicitaram-se os objetivos e a necessidade do uso do gravador, e garantidos o anonimato e a confiabilidade das suas respostas, indicando-lhes que elas seriam analisadas no seu conjunto.

O primeiro instrumento a ser aplicado foi a técnica de associação livre de palavras, seguido da entrevista. Os instrumentos foram aplicados de forma individual na própria Secretaria de Saúde por um pesquisador previamente treinado e qualificado; o tempo de aplicação foi, em média, de 25 minutos para cada participante. Informa-se, ainda, que não houve recusa por parte de nenhum ACS. Antes da apresentação do estímulo já mencionado, foi feita uma simulação utilizando um exemplo, com o intuito de familiarizar o participante acerca da funcionalidade do instrumento. Em seguida, foi apresentado o estímulo indutor, seguido da questão, "o que lhe vem à mente (cabeça) quando digo a palaura álcool?"; "Fale as cinco

Tabela 1 - Causas do uso do álcool

\begin{tabular}{lcc}
\hline & Categoria e Subcategorias & \multicolumn{2}{c}{ ACS's } \\
\cline { 2 - 3 } & f & 21 \\
Prazer & 16 & 26 \\
Curiosidade & 20 & 33 \\
Disponibilidade & 25 & 20 \\
Diversão & 15 & 100 \\
\hline Total & 76 & 20 \\
\hline
\end{tabular}


primeiras palavras que para o Sr (a) lembra o álcool'. É válido mencionar que na presente pesquisa convencionou-se o tempo máximo de 01 (um) minuto para a evocação das palavras associadas ao estímulo indutor, perfilando 01 minuto, por cada participante, para responder ao teste de associação livre de palavras.

\section{Análise dos Dados}

No que se refere à análise dos dados das entrevistas, utilizou-se a análise de conteúdo temática proposta por Bardin (2002), cujo objetivo é compreender o sentido das comunicações e suas significações explícitas e/ou ocultas. Seu procedimento visa, ainda, obter a sistematização e descrição do conteúdo das mensagens, que permitem a inferência de conhecimentos relativos às condições de produção/recepção (variáveis inferidas), analisados quantitativamente por meio da análise das freqüências e percentuais.

A análise das unidades temáticas por meio dessa técnica pressupõe o desenvolvimento das seguintes etapas operacionais: constituição do corpus - formado pelas entrevistas; leitura flutuante - consiste numa leitura superficial do material obtido, com a finalidade de tomar conhecimento dos dados para, em seguida, realizar leituras mais orientadas que permitam a impregnação, por parte do pesquisador, dos dados obtidos; codificação e recortes - dá-se a partir da decomposição do corpus e da codificação dos temas, agrupando-se o material em subcategorias e categorias simbólicas; categorias e subcategorias - consiste na categorização do corpus que, neste estudo, foi agrupado de acordo com o consenso de dois juízes especialistas.

Os dados coletados pela técnica de associação livre foram processados pelo software Tri-Deux-Mots (Cibois, 1998), versão 2.2, que permite a visualização gráfica, tanto das variáveis fixas (sexo, idade e estado civil), bem como das variáveis de opinião, crenças, estereótipos, enfim, o conhecimento prático, enunciado pelos participantes ao estímulo indutor e analisado através da Análise Fatorial de Correspondência (AFC), um procedimento metodológico que consiste em distinguir os vínculos estabelecidos entre as características dos indivíduos que constituem um grupo e suas respostas a um determinado objeto psicossocial.

\section{Resultados e Discussão}

\section{Dados Apreendidos pela Técnica da Entrevista}

As RS acerca do álcool elaboradas pelos ACS's, com base no material coletado pelas entrevistas e ponderadas pela análise temática de conteúdo, de acordo com o consenso de dois pesquisadores, resultaram em 03 categorias empíricas e 12 subcategorias.

$\mathrm{Na}$ primeira categoria, que se refere às Causas do Uso do Álcool (CUA), houve a emersão de quatro subcategorias: Diversão; Disponibilidade; Curiosidade e Prazer. Os dados da tabela 1 revelam que os ACS's apontam 20\% para Diversão, 33\% Disponibilidade, 26\% para curiosidade e $21 \%$ na subcategoria para Prazer.

Os ACS's representaram as causas do uso do álcool nas suas falas: ( ) começa com curiosidade e divertimento, depois fica dependente ( ) o álcool no início dá prazer, mas pode levar ao alcoolismo ( ) pela questão de ser uma droga legal isso incentiva muito seu uso ( )".

Dados semelhantes ao da presente pesquisa, com relação ao uso do álcool associado à questão do prazer, foram encontrados em estudo com adolescentes pernambucanos no qual se observou que a principal motivação para o uso do álcool pela primeira vez eram as sensações prazerosas desempenhada pela droga nos seus usuários (Quintela \& cols., 2004).

No que diz respeito ao destaque dos ACS's, as subcategorias Disponibilidade e Diversão, provavelmente sejam pertinentes na medida em que se trata de uma droga dita lícita, que o seu uso é incentivado e aceitável pelos diversos segmentos da sociedade. Fato corroborado no I Levantamento Domiciliar acerca do Uso de Drogas realizado pelo CEBRID, que constatou que $53,2 \%$ dos brasileiros já utilizaram a substância psicoativa alguma vez na vida (Carlini, Galduróz \& Noto, 2001).

A segunda categoria diz respeito às Conseqüências

Tabela 2 - Conseqüências na vida dos usuários da álcool

\begin{tabular}{lcc}
\hline & Categoria e Subcategorias & \multicolumn{2}{c}{ ACS } \\
\cline { 2 - 3 } & $\mathrm{f}$ & $\%$ \\
\hline Familiares & 50 & 36 \\
Orgânicas & 42 & 31 \\
Profissionais & 25 & 18 \\
Sociais & 20 & 15 \\
\hline Total & 137 & 100 \\
\hline
\end{tabular}

Psico-USF, v. 11, n. 1, p. 85-94, jan./jun. 2006 
Tabela 3 - Formas de tratamento dos usuários do álcool

\begin{tabular}{lcc}
\hline & \multicolumn{2}{c}{ ACS' } \\
\hline Médico & $\mathrm{f}$ & $\%$ \\
\cline { 2 - 3 } Psicossocial & 35 & 27 \\
Grupos de Apoio & 25 & 19 \\
Campanhas Preventivas & 50 & 39 \\
\hline Total & 20 & 15 \\
\hline
\end{tabular}

na Vida do Usuário de Álcool (CVUA), com três subcategorias, a saber: Familiares, Orgânicas, Sociais e Profissionais. Os dados apresentados pelos ACS's quanto às conseqüências distribuem-se em Familiares (36\%), Orgânicas (31\%), Sociais (18\%) e Profissionais (15\%).

As RS dos ACS's foram majoritárias quanto às repercussões familiares causadas pelo álcool. De forma consonante, Fender (1996) argumenta que o sistema familiar afeta e é afetado pelo uso de psicotrópicos, de modo que a maioria dos familiares passa a considerar a farmacodependência como algo central nas relações psicoafetivas, dificultando seu processo evolutivo e o equilíbrio familiar.

Entre as unidades temáticas das falas dos ACS's foi possível destacar que as RS das conseqüências do uso do álcool atingem, principalmente, os elementos familiares e orgânicos:

\section{( ) Eu tenho algumas pessoas na minha familia que são viciadas ( ) fica difícil para eles se libertarem ( ) É que dá muito prejuízo ( ) Destrói sua família ( ) Fica uma pessoa assim em situações desagradáveis ( ) prejudica muitos lares ( ) Ele (álcool) também leva, na maioria das vezes à destruição dos lares ( ) porque o chefe da fa- milia chega em casa bêbado ( ) a pessoa falta no trabalho ( ) o álcool traz uma série de violência para família ( ) "É uma droga ( ) e eu não aconselharia ninguém a usar porque é prejudicial ( ) faz mal às pessoas ( ) Pode levar à Cirrose ( ) Cirrose leva à morte ( ) Morte ( ) porque onde tem álcool tem briga ( ), tem morte ( ), é uma bebi- da prejudicial à saúde ( ).}

Pode-se observar que os ACS's mencionaram as conseqüências advindas do uso abusivo do álcool nos seus aspectos orgânicos, profissionais, sociais e familiares. Diante disso, o alcoolismo trata-se de um fenômeno complexo e não apenas de uma doença devendo ser inserido numa perspectiva sociohistórica, que se preocupe também com os aspectos legais, familiares, de trabalho, econômico e de saúde (Barros, 2004; Fender, 1996).

Os ACS's destacaram as conseqüências para o usuário do álcool ancorado na perspectiva orgânica, de modo que o conhecimento elaborado e compartilhado pelo grupo de pertença acerca da substância psicoativa se deva provavelmente, a sua prática profissional e cotidiana na promoção e prevenção em saúde (Jodelet, 2001).

De forma consonante com os ACS's acerca das conseqüências profissionais e sociais, Bertolote (1997) aponta que o uso do álcool está comumente associado a problemas sociais, como dirigir alcoolizado, agressões físicas e embriaguez em via pública. Destacam-se também os problemas profissionais decompostos pela falta de assiduidade ao trabalho, baixa produtividade e problemas de acidente de trabalho.

A última categoria apreendida, conforme tabela 3, Tratamento do Usuário do Alcool (TUA), foi subdividida em quatro subcategorias: Tratamento Médico; Tratamento Psicossocial, Campanhas Preventivas e Grupos de Apoio. Denota-se que os ACS's destacaram as Campanhas Preventivas, com 39\%; Tratamento Médico, com 27\%; Tratamento Psicossocial, com 19\%; e Grupos de Apoio, com 15\% das unidades temáticas.

Pode-se observar nas falas dos atores sociais desta pesquisa:

\section{só com muita força de vontade pode até sair participando do A.A. pode chegar a um ponto de sair ( ) mas muitos saem mas já estão com uma vida completamente destruída, só campanhas preventivas, panfletos ( ) o alcoólatra preci- sa de tratamento médico ( ) um tratamento que trabalhe a família, individuo e sociedade ( ).}

Os discursos dos ACS's destacam as Campanhas Preventivas, como intervenções no tratamento do usuário do álcool, ação preventiva estimulada pela Secretária Nacional Antidrogas - SENAD (2001a). No entanto, mencionaram que não dispõem, na sua prática profissional, de panfletos, material informativo, vídeos, que auxiliem na prevenção primária ao uso indevido de drogas.

No que diz respeito às formas de Tratamento Psicossocial e Médico elencadas pelos ACS's, as intervenções terapêuticas são bastante utilizadas na atualidade da psicofarmacodependência de forma interdepen- 
F2

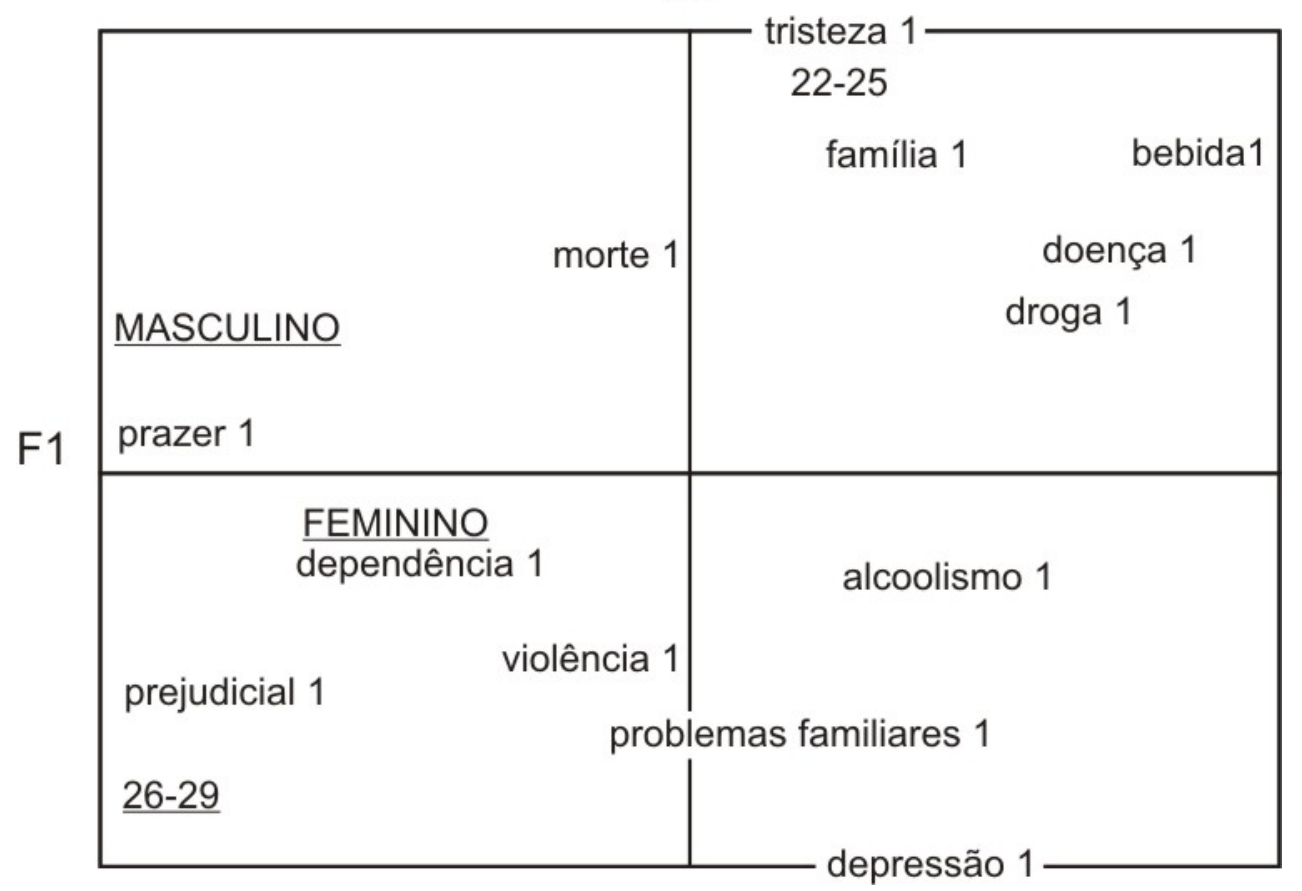

Figura 1 - Plano fatorial de correspondência das representações sociais do álcool pelos ACS’s

dente, de modo que os profissionais de saúde interagem numa visão holística do fenômeno das drogas, envolvendo usuários, a droga em si e seus familiares (Coutinho, Araújo \& Gontiés, 2004; Barros, 2004; Edwards, 1995; Ramos \& Pires, 1997).

Os grupos de Apoio também foram mencionados pelos ACS's como forma de atuação no tratamento do alcoolismo, fato corroborado em pesquisa realizada na realidade paraibana por Barros (2004) sobre as RS do alcoolismo por parte de profissionais das áreas de saúde e humanas.

\section{Dados Apreendidos pela Associação Livre de Palavras}

Os resultados coletados por meio do teste de associação livre de palavras, enquanto instrumento de apreensão de significados do conhecimento prático, possibilitou, juntamente com as variáveis fixas, a emersão de campos semânticos sobre as RS do Álcool, conforme pode ser observado na Figura 1, através dos dois fatores (F1 e F2), e analisados através da Análise Fatorial de Correspondência.

$\mathrm{Na}$ técnica da AFC, tornam-se evidenciadas as correlações (positivas e negativas) existentes entre diferentes grupos de sujeitos, em função das respostas características de determinado grupo, encontrando-se agrupadas e, simultaneamente, em oposição a um outro grupo com características do primeiro. Em estatística, as respostas (variáveis de opinião) são denominadas de modalidades de contribuição à construção dos fatores ou eixos que constituem o plano fatorial. Assim, o somatório de todas as palavras evocadas $(\Sigma=276)$ pelo conjunto dos participantes $(\mathrm{N}=70)$ que compõem a amostra da pesquisa relativa ao estímulo indutor é analisada pela frequêencia e importância relativa às variáveis fixas (gênero e idade), determinando o espaço fatorial ou gráfico.

O fator 1 (F1), na linha horizontal, em negrito, concerne ao fator majoritário de maior poder explicativo, com $47 \%$ da variância total das respostas. No que tange ao fator 2 (F2), na linha vertical, em itálico, possui $22 \%$ da variância total das respostas.

Nesse fator percebe-se que houve maior contribuição dos ACS's do gênero feminino na explicação, com 120 palavras evocadas. No que tange às idades, os ACS's que compreendem a faixa etária entre 22-25 contribuíram, de forma majoritária, para o fator 2, com 156 palavras evocadas. $\mathrm{Na}$ totalidade, os dois fatores têm poder explicativo de $69 \%$ de significância, portanto, possuem parâmetros estatísticos com consistência interna e fidedignidade, tendo em vista pesquisas realizadas no âmbito das RS (Nóbrega \& Coutinho, 2003).

$\mathrm{Na}$ parte horizontal direita, em negrito, do gráfico 1, encontra-se o campo semântico das RS do álcool (E1) elaborado pelos ACS's do gênero feminino na faixa etária de 26-29, em que ancoraram suas representações como uma substância psicoativa que é prejudicial á saúde, com possível instalação do alcoolismo e que pode desenca- 
dear depressão no usuário da droga, bem como o aumento da violência.

Minayo e Deslandes (1998) ao dissertarem acerca da associação entre o uso do álcool e violência, sinalizam que o setting (ambiente social), determinados segmentos e situações específicos contribuem para a correlação positiva entre uso do álcool e comportamentos violentos. Faz-se necessário também considerar os aspectos relacionados à personalidade (set) e expectativas ao se fazer uso da droga.

Ainda nesse fator, destacam os ACS's do gênero masculino que ancoraram suas representações pautadas na obtenção do pražer que a droga propicia ao usuário, fato interessante e também verificado nas entrevistas, uma vez que este componente comumente não é associado ao uso de psicotrópicos. Infere-se que pelo fato de tratar-se de uma droga lícita tenha contribuído para tal associação verificada nas RS do álcool.

No que tange aos ACS's de ambos os gêneros que compreendem a faixa etária de 22-25 anos, pôde-se verificar que os atores sociais mencionaram que o álcool é uma bebida e que pode desenvolver inúmeros problemas familiares nos usuários. O uso do álcool, freqüentemente, ocasiona problemas nos vínculos socioafetivos, de modo que atingem os usuários e seus familiares (Edwads, 1995; SENAD, 2001b).

De forma semelhante aos dados encontrados nas entrevistas, os ACS's no teste de associação ancoraram suas RS nos elementos concernentes aos problemas familiares, prejudicial à saúde e violência. De modo que as RS verificadas entre os atores sociais desta pesquisa acerca do álcool aparecem como um conhecimento que não se caracteriza por uma contraposição ao saber científico, havendo uma dialética entre o conhecimento consensual (senso comum) e o reificado (científico) (Moscovici, 2003).

Ademais, os resultados apreendidos por esse instrumento, além de corroborar, complementam os dados apreendidos nas entrevistas acerca das RS do Álcool. Nesse sentido, o álcool foi representado enquanto uma droga que pode trazer inúmeras conseqüências psicossociais, profissionais, familiares e orgânicas. As conseqüências apontam para a necessidade da inserção dos ACS's na educação preventiva em saúde, sendo interlocutores entre gestores em saúde e a comunidade.

\section{Considerações finais}

O presente trabalho versou sobre as RS do álcool entre ACS's. Os dados apreendidos entre os ACS's possibilitaram representações consensuais e de particularidades, de acordo a vivência de sua atuação na saúde preventiva. Através das RS do álcool apreendidas pela técnica de associação livre de palavras e pelas entrevistas, pôde-se ter acesso às opiniões, crenças, atitudes, e imagens, verificando-se que o conhecimento elaborado pelos ACS's foi ancorado num paradigma composto de três vias: causas, conseqüências e tratamento acerca do uso do álcool.

Um aspecto que merece destaque entre os dados obtidos acerca das causas do uso do álcool concerne ao fato dos ACS's mencionarem o prazer como fator impulsionador para o uso do psicotrópico. O aspecto hedonista é algo inerente às drogas lícitas e ilícitas, no entanto, percebe-se que, comumente, não é mencionado pelos profissionais de saúde como propiciadores para que os usuários busquem sensações prazerosas nas drogas.

No que diz respeito às conseqüências advindas do uso do álcool, verificou-se uma relação indissociável entre o usuário e o seu entorno socioafetivo, profissional e familiar. Na relação dialética entre os pólos, a substância psicoativa é representada como prejudicial à saúde e a sua ingestão de forma abusiva/indevida pode ocasionar violência, depressão e até a morte em seus usuários, podendo ocasionar problemas laborais (relacionadas ao mundo do trabalho), como: acidentes de trabalho, desemprego, demissão e absenteísmo.

No que tange ao tratamento dos usuários do álcool, verificou-se que os ACS's apontaram, de forma majoritária, as campanhas preventivas, principalmente, as intervenções no âmbito da educação primária em saúde, provavelmente devido às intervenções freqüentemente desenvolvidas pelos ACS's, como a realização de palestras e distribuição de material informativo entre os moradores das comunidades.

Através das RS elaboradas pelos atores sociais desta pesquisa, percebe-se que o uso do álcool é algo preocupante na comunidade. Denota-se nos relatos de casos a presença do fenômeno do alcoolismo entre os moradores, bem como nos próprios familiares dos agentes de saúde. Faz-se necessário uma intervenção por parte dos gestores em saúde, com intuito de informar aos usuários, familiares e sociedade em geral, sobre os danos causados pelo álcool.

Fato que merece destaque diz respeito à falta de qualificação profissional para atuar na prevenção primária ao uso abusivo de drogas. Os ACS's mencionaram a carência de cursos de atualização sobre substâncias psicoativas e a sua atuação no organismo humano. Esses dados vão de encontro ao que é preconizado pelo PACS (Programa de ACS's), do Ministério da Saúde, que determina como ação dos ACS's a orientação na prevenção primária ao uso indevido de drogas. Contudo, os ACS’s dispõem apenas de conhecimentos básicos sobre os danos causados pelas drogas, apontando, as- 
sim, para a necessidade de um maior número de cursos de qualificação acerca da temática, possibilitando um melhor exercício de seu papel de multiplicador de informações.

Verificou-se que, apesar de não ter sido objeto de pesquisa do presente estudo, no decorrer dos contatos efetivados junto aos ACS's, uma ênfase na falta de incentivo e reconhecimento pelos gestores municipais, ao seu importante papel como agentes propiciadores de melhores condições de saúde para a população, refletida na precariedade de recursos materiais que auxiliariam no exercício de suas atividades cotidianas.

Destaca-se a importância do uso de multimétodos que possibilitam a apreensão de conteúdos verbais e latentes, posto que a desejabilidade social dificulta seu acesso nas pesquisas pela natureza subjetiva dos fenômenos psicossociais. Sugere-se, de forma parcimoniosa, que os resultados desta pesquisa contribuam para a formulação de estratégias na implementação de políticas públicas de educação e promoção em saúde para os ACS's, de modo a fornecer embasamento para os gestores em saúde no intuito de minimizar o uso abusivo do álcool, uma vez que se trata de uma droga dita lícita, acessível economicamente e de uso aceitável na sociedade brasileira.

\section{Referências}

Abric, J. (2000). Abordagem estrutural das Representações Sociais. Em A. S. P. Moreira \& D. C. Oliveira, (Orgs.). Estudos interdisciplinares de representação social (pp. 27-38). Goiânia: AB.

Bardin, L. (2002) Análise de Conteúdo. Lisboa: Edições 70 .

Barros, D. R. (2000) Representações Sociais sobre o Alcoolismo: Um Estudo com Alcoolistas Hospitalizados. (Monografia em Psicologia Não-Publicada). João Pessoa, PB: Universidade Federal da Paraíba.

Barros, D. R. (2004). Representações Sociais de profissionais das áreas de humanas e da saúde acerca do alcoolismo. (Dissertação de Mestrado em Psicologia Social NãoPublicada). João Pessoa: Universidade Federal da Paraíba.

Bertolote, J. M. (1997). Conceitos em alcoolismo. Em S. P. Ramos \& J. J. Bertolote (Orgs.). Alcoolismo Hoje (pp. 17-31). Porto Alegre: Artes Médicas.

Carlini, E.; Galduróz, J. C. F. \& Noto, A. R. (2001) I Levantamento Domiciliar sobre o Uso de Drogas Psicotrópicas no Brasil: Estudo envolvendo as 107 maiores cidades do País. São Paulo: CEBRID - UNIFESP.
Cibois, P. (1998). L'analyse factorielle. Paris: PUF, Collecion “Que sais-je?”.

Coutinho, M. P. L.; Araújo, L. F. \& Gontiès, G. (2004). Uso da Maconha e suas Representações Sociais: estudo comparativo entre universitários. Psicologia em Estudo, 9, 469-477.

De Rosa, A S. (1988). Sur l'usage des associations libres dans l'étude des représentations sociales de la maladie mentale. Connexions, 51, Rome:Université de Rome.

Di Giacomo, J. P. (1981). Aspects méthodologiques de l'analyse des répresentations sociales. Cahiers de Psychologie Cognitive, 1, 397-422.

Edwards, G. (1995). O tratamento do Alcoolismo. São Paulo: Artes Médicas.

Fender, S. A. (1996). A importância do envolvimento de familiares no tratamento de dependentes de drogas: uma experiência no PROAD. Em D. X. S. Filho \& M. Gorgulho (Orgs.). Dependência: compreensão e assistência às toxicomanias (pp. 81-92). São Paulo: Casa do Psicólogo.

Herzlich, C. (1986). Représentations socials de la santé et de la maladie et leur dynamique dans le champ social. Em W. Doise \& A. Palmonari (Orgs.). L'etude des representations socials (pp. 70-97). Neuchâtel-Paris: Delachaux \& Niestlé.

Jodelet, D. (2001). Representações Sociais. Rio de Janeiro: EdUERJ.

Le Boudec, G. (1984). Contribuition à la méthodologie d'étude des représentations sociales. Cabiers de Psycologie Cognitive, 4, 245-272.

Minayo, M. C. S. \& Deslandes, S. F. (1998). A complexidade das relações entre drogas, álcool e violência. Cadernos de Saúde Pública, 14, 35-42.

Ministério da Saúde (2000). Programa ACS's. Brasília: Ministério da Saúde.

Moscovici, S. (1978). A Representação Social da Psicanálise. Rio de Janeiro: Zahar.

Moscovici, S. (1984). Psycologie Sociale. Paris: PUF.

Moscovici, S. (2003). Representações Sociais: investigações em psicologia social. Petrópolis-RJ: Vozes.

Nóbrega, S. M. \& Coutinho, M. P. L. (2003). O Teste de Associação Livre de Palavras. Em M. P. L. Coutinho \& cols. (Orgs.). Representações Sociais: abordagem interdisciplinar (pp. 67-77). João Pessoa: EdUFPB.

Quintela, C. R.; Barros, U. F.; Galindo, R. D. G. \& Sobreira, W. D. (2004). Adolescentes e o uso de bebida alcoólica: perfil epidemiológico e fatores associados. (Monografia de Especialização em Saúde da Família

Psico-USF, v. 11, n. 1, p. 85-94, jan./jun. 2006 
Não-Publicada). Recife, PE: Universidade do Pernambuco.

Ramos, S. P. \& Pires, M. E. F. (1997). A família alcoólica e seu tratamento. Em S. P. Ramos \& J. M. Bertoloti (Org.). Alcoolismo hoje (pp. 207-216). Porto Alegre: Artes Médicas.

Sá, C. P. de (1993). RS: o conceito e o estado atual da teoria. Em M. J. Spink (Org.). O conhecimento no cotidiano. As Representações Sociais na perspectiva da Psicologia Social (pp. 19-43). São Paulo: Brasiliense.

Secretária Nacional Antidrogas (2001a). Um guia para a família. Brasilia: SENAD.
Secretária Nacional Antidrogas (2001b). Alcool: o que você precisa saber. Brasília: SENAD.

Silva, J. A. \& Dalmaso, A. S. W. (2002). Agente Comunitário de Saúde: o ser, o saber, o fazer. Rio de Janeiro: Editora Fiocruz.

Tura, L. F. R. (1998). AIDS e estudantes: A estrutura das representações sociais. Em D. Jodelet (Org.). AIDS e representações sociais: $A$ busca de sentidos (pp. 121154). Natal: EDUFRN.

Recebido em fevereiro de 2005 Reformulado em outubro de 2005 Aprovado em fevereiro de 2006

Sobre os autores:

Alessandra Ramos Castanha é doutoranda em Psicologia pela USP - Ribeirão Preto-SP, mestre em Psicologia Social pela UFPB, especialista em Psicologia Hospitalar, licenciada em Psicologia pela UNICAP.

Ludgleydson Fernandes de Araújo é mestre em Psicologia Social, especialista em Gerontologia, licenciado em Psicologia pela UFPB. 